\title{
Hybrid Psychology: The marriage of discourse analysis with neuroscience. ${ }^{1}$ \\ Psicología híbrida: La unión del análisis del discurso con la neurociencia
}

\author{
Rom Harré \\ Georgetown University \\ harre@georgetown.edu
}

\section{Resumen}

A lo largo del siglo $X X$, la psicología académica parece separarse en dos dominios radicalmente distintos e irreconciliables. La psicología discursiva se centró en la gestión de significado en un mundo de normas, mientras la neuropsicología se centró en la investigación del cerebro y de los procesos cognitivos. Estos dos dominios pueden reconciliarse en una ciencia híbrida que las reúna en una síntesis más potente, logro que los psicólogos no han conseguido con anterioridad.

En este artículo, se entiende que la psicología híbrida depende de la intuición de que mientras que el cerebro puede asimilarse en el mundo de las personas, las personas no pueden asimilarse en el mundo de las estructuras celulares y los procesos moleculares.

El proyecto de crear una ciencia híbrida, en la que el símbolo incorpore la capacidad de que los seres humanos sean sometidos a un plan unificado de los aspectos orgánicos de los miembros de la especie homo sapiens, exige la disolución del problema mentecuerpo, de alguna manera dejando de lado como una ilusión, basada en una premisa errónea.

Palabras clave: Psicología Híbrida; Análisis del discurso; Neurociencia; Lenguaje; Mente

\section{Abstract}

As the 21st Century opened the controversial and unstable discipline of 'academic psychology' seemed to separating into two radically distinct and perhaps irreconcilable domains. Discursive psychology focused on the management of meaning in a world of norms while Neuropsychology focused on the investigation of brain and cognitive processes. These two domains can be reconciled in a hybrid science that brings them together into a synthesis more powerful than anything psychologists have achieved before.

In this paper means Hybrid psychology depends on the intuition that while brains can be assimilated into the world of persons, people cannot be assimilated into the world of cell structures and molecular processes.

The project of setting up a hybrid science, in which the symbol using capacities of human beings are brought into a unified scheme with the organic aspects of members of the species homo sapiens, demands the dissolution of the mind-body problem, somehow setting it aside as an illusion, based on a mistaken presupposition.

Keywords: Hybrid Psychology; Discourse analysis; Neuroscience; Language; Mind

\section{Introduction}

As the $21^{\text {st }}$ Century opened the controversial and unstable discipline of "academic psychology" seemed to separating into two radically distinct and perhaps irreconcilable domains. Discursive psychology focused on the management of meaning in a world of norms while Neuropsychology focused on the investigation of brain processes loosely correlated with intuitively identified cognitive processes. These two domains

\footnotetext{
${ }^{1}$ This paper is a resume of the argument presented in Harré (2004).
} 
can be reconciled in a hybrid science that brings them together into a synthesis more powerful than anything psychologists have achieved before.

The fundamental principle of discursive psychology is that the instruments of cognition are symbols. The languages of everyday life are the most important symbolic tools. Hybrid psychology depends on the intuition that while brains can be assimilated into the world of persons, as among the instruments people use for carrying out many of their projects, people cannot be assimilated into the world of cell structures and molecular processes. To suppose that they can be has been called the "mereological fallacy" ascribing attributes of wholes to some of their parts. People think, brains, parts of people, do not. People drive cars, their hands and feet do not (Bennett \& Hacker, 2007).

\section{The Central Role of Language}

People use symbolic systems of various kinds as instruments for thought. However, many philosophers and psychologists have believed that thought exists independently of the symbolic forms in which it is clothed and by means of which it is expressed. Language, though of great importance, is not the only medium of cognition. Sometimes a cognitive act, such as deciding which dish to choose from the menu, is achieved by manipulating symbols of other kinds, such as images and mental pictures. Sometimes symbols have a material embodiment in compasses and maps.

Discursive psychology is based on the principle that whatever media people use, for instance, sketching a map to convey so a visitor how to find one's apartment, the symbolic object is intentional, that is has a conventional meaning, and it is normative, subject to standards of correctness. The visitor must understand the sketch not just as a pattern of lines on paper, but as a representation of the neighboring terrain, with the presumption shared by host and visitor alike, that the sketch is within the demands of the task, accurate..

\section{Language as the Medium of Public Expression of Private Experience}

If we are to be able to make a study of public language use as a method for investigating psychological phenomena, some of which are private, then we must have a suitable account of the relation of the public activities of speaking and other symbolic acts to the private activities and states they express. The notion of "expression" that will serve as the basis of that account, restoring the role in had in nineteenth century psychology (Danziger, 1990). I will show how a simple extension of Wittgenstein's famous Private Language Argument opens the way to a general distinction between using language to describe our private experience and using it to express that experience. This distinction will serve to give general support to the discursive method for exploring both private and public cognitive acts.

Language use is not only public, as in conversation, producing an interpersonal realm of meanings. but there is also a private realm of human experience, and private uses of symbolic systems that play a key part in its production. How are the features of that world to be studied by psychologists and philosophers? To understand the views of discursive psychologists on this issue we need to draw on another important distinction that plays a major role in the psychological aspects of Wittgenstein's later philosophy. This is the distinction between expression and description. 
The distinction is an important ingredient in the famous Private Language Argument (Wittgenstein, 1953, pp. 240-315) in the course of which several points of importance are established. The general question Wittgenstein is discussing is whether a language could exist if meaning was established solely by pointing to exemplars, drawing the attention of the learner to examples of what a word is used to refer to. This idea seems reasonable when the meaning of words for large public objects like palaces or elephants are being taught. But could it work if the exemplars were strictly private somethings, such as private feelings? If words could be learned by pointing to such feelings then a strictly private language would be possible. But if the exemplars are strictly private they could not be used to teach anyone else the use of the relevant words, or even to serve as stable basis for the speaker's own practice. How do we learn them, if we cannot learn them by pointing to public examples?

The process of developing a vocabulary for private feelings, begins, he suggests with natural expressions of pain, joy, and so on. As a child develops it learns to substitute vocalisations and finally verbal formulae, that function in the same way as the natural expressions they displace. The words "I'm so happy" express my happiness rather than describe my private feelings. Of course when I say such a thing I do have private feelings to express. But the relation between the verbal act and the feeling is not that of description to object described. If it were a case of description the words and the objects they describe would have been independent of one another. But if my words express my feelings, just as laughing and singing might, then, ceteris paribus, they are part of a whole, a complex of feelings and behavioural tendencies no part of which could be left out of what it is to be happy.

\section{The domain of psychology}

People are actively producing streams of thought and action, both public and private, embedded in a flux of bodily feeling. We routinely and unthinkingly partition this stream in all sorts of ways. We express a belief, we claim have a memory, we make a decision, we have a temper tantrum and so on. Psychologists cannot but make use of these everyday partitions, for they define the subject matter of their studies. If we could not tell a temper tantrum from a memory claim there would be no psychology, indeed no human life at all as we know it. This picture is filled out by the idea that we should think of our lives as narratives, lived and told stories shaping what we do. The metaphor of life as narrative is one the most important organizing concepts of the discursive turn for many new-wave psychologists, for instance Jerome Bruner (1986), the Loughborough school (Edwards and Potter, 1992) and so on. From this point of view perception is also a kind of action, something that a person does rather than the result of passively receiving visual, auditory, tactile and so on stimuli. We perceive by exploring the flux of visual, auditory, tactile and so on sensations, as the perceptual system seeks invariants, the shadows cast by material things and processes (Gibson, 1966).

\section{The Act-Action Distinction}

Can we find a general principle by means of which the stream of human activity should be partitioned in the most psychologically illuminating way? It seems natural to adopt the act/action distinction as a way of displaying one possible sequence of the elements of behaviour and thought, elements that are consonant with the root metaphors of meanings and rules for their correct use. Actions are what people produce intentionally. Acts are the meanings or forces of actions. A nod is an action, which, in the appropriate circumstances can mean that one agrees with what has been proposed. In other circumstances the very 
same action can mean something else. Acts not only constitute narratives, but are constituted by the story-line that the narrative realizes. In the garden of Gethsemane a kiss is a betrayal. In greeting the Pope it is a mark of submission and respect.

Having partitioned the stream of activity into a sequence of elements, relative to the story-line we are taking to be realized in the stream of activity, the question of how the elements are related must be taken up. Within the general framework of the root metaphors are various subsidiary concepts that are relevant to this problem. For example there are action patterns produced as the result of rule-following, as the result of living out a culturally specific story-line such as the "heroic quest", and so on.

In summary we can say that the idea of life as discourser involves the following main theses:

a. We produce both public and private streams of meaningful acts.

b. Some are conveyed verbally and some non-verbally, by gestures, postures, diagrams and so on.

c. Public and private, verbal and non-verbal acts fall under the same general system of categories, both analytically and explanatorily. Acts are the meanings of actions, determined in time and place by the identity of the actors and the nature of the context.

\section{Mind as Discourse}

The choice of "discourse" as the leading metaphor for human thought and action is intimately related to the idea that the flow of intentional actions is the very "stuff of mind". Having a mind is to be master of certain discursive practices, for example, remembering. All sorts of practices fall under this heading. Some are linguistic, some are not. All are intentional, that is all are meaningful, and all are subject to standards of correctness, propriety and so on. The sort of practice with which cognitive activities are being carried on, linguistic or non-linguistic, will determines the choice of analytical and explanatory models for the conduct of research.

According to the "discursive" point of view as sketched above, psychology is primarily the study of processes -streams of human actions and interactions- which can be understood in terms of their meanings for the actors and interactors and the norms and traditions that are generally accepted by the people involved and which shape their actions. Many of these streams of meaningful actions can be made sense as living out narratives, story-lines well known in the culture. Within this general scheme conversation is the most useful, but not the only model for analyzing such streams of action. Adopting this model for a research program invites the researchers to treat all that people do collectively and individually, privately and publicly, as if it were a kind of conversation, that is consisted of meaningful exchanges constrained by a local system of rules and conventions. There are many different jobs that language can be used for. We use words to give orders, to make apologies, to issue invitations, to express our hopes and fears, as well as to describe and explain matters in our environments.

How is it possible for a person to do all these things? Each human being must have acquired a body of knowledge, appropriate to the local culture, which can be thought of a resource of getting the performance right. Rarely is this body of knowledge accessed consciously. Mostly it is immanent in the activities of the actors, as habits of mind and action. This is not a revival of behaviorism in an up-dated form --the content of a body of knowledge is made up of meanings and rules. Its function is normative! 
This leads directly to the study of what people must know and what skills they must possess to be able to produce the required actions. Complementary to each mode of collective action there must a repertoire of individual skills and dispositions. One of the most difficult questions faced by psychologists is what form this knowledge takes. Is the common metaphor of a "store of knowledge" of any value, or does its presupposition that items of knowledge are retained as knowledge, that is in propositional form, liable to lead us astray?

Continuing the "discourse" metaphor, we will find Wittgenstein's concept of a "grammar" helpful. We have come across the term already, for the cluster of rules, implicit and explicit, which shape what we do, say and think in certain contexts. Sometimes a person is consciously following an instruction. This is one sense in which the word "rule" can be taken. It can also be used as a metaphor for cases in which a person or group of people act in an orderly way by habit, custom, convention and so on, in cases where there is no attention to explicit rules. Richard Shweder (1991) has identified a class of shaping principles that he calls "contingent universals". He finds such principles in the customs of cultures other than our own, and of course they could be found in ours too. These seem to be just the sort of principles that would be found in a Wittgensteinian grammar. Shweder illustrates the idea of "contingent universals" with some of the taken-for-granted conventions of for living one finds in a small Indian town. It would be unthinkable to eat fish on the day of one's father's funeral, or to have one's hair cut for two weeks thereafter. People would no more dream of calling these "rules" into question than we would on the principle that two distinct things cannot be in the same place at the same time. Of course, dear reader, you have already been thinking of the kinds of things that would violate this rule! Its is universal for some kinds of things, but not for others, just as the funeral customs of an Indian town are universal for some kinds of people, the Hindus who live there, and not for others, their Muslim neighbours.

The final step in a psychological study of some cognitive procedure, say remembering or classifying, after the analysis of the streams of activity in which the procedure is carried on into elementary actions and acts, would be the proposal of a "grammar" or grammars expressing the norms that are evident in what people are doing. There are both tacit and explicit grammars. Michael Polanyi (1958) and Harold Garfinkel (1967) have pointed out that in order to use any explicit technique one must make use of a repertoire of tacit knowledge. When such knowledge is formulated explicitly the use of that knowledge as an explicit guide to thought and action will depend on yet another corpus of tacit knowledge. What was explicit in one context may be tacit in another.

\section{The grammars of everyday life}

Contemporary Western life, conceived as discourse, seems to be shaped by three main grammars.

A Person or P-grammar, in which persons are the basic particulars and originating sources of activity. It comprises the rules for the use of the tribal dialects and idiolects of everyday life. Among some of the specialised dialects of this generic grammar are the idioms of the courtroom, Freudian psychotherapy, the Internet and so on.

A main feature of P-grammars is the way that responsibility is dealt with. This is particularly important for a philosophy of psychology, since the transition from infancy to maturity of a being that has native agentive powers and acts teleologically, occurs along the dimension of growing responsibility for what it does. Kelly Shaver (1985) has proposed an analysis of responsibility dimensions that will do very well as 
a working grammar for much of the P-grammar of current English language folk psychology ${ }^{2}$. The attribution of responsibility according to Shaver runs as follows:

A judgement made about the moral accountability of a person of normal capacities, which usually but not always involves an agentive connection between the person being judged and some morally disapproved action or event (Shaver, 1985, p. 66)

Another example of the use of the P-grammar is in ordinary cases of remembering. Only people remember, not brains. To say "I remember .. " is to claim some kind of authority, to commit myself to what I assert about the past. It involves my moral standing as a person. Playing tennis is another example. The exchange of shots is constrained by conventions of meaning: "On the line is out"; and of procedure: "Change ends after four games". Scores accrue to people and it is people who play shots, good and bad, for which they are responsible, and so on.

A Molecular or M-grammar, in which molecules and molecular clusters are the basic particulars and originating sources of activity. Among the dialects shaped by M-grammar is human physiology and molecular biology. Discourse framed in this grammar includes such attributions of agency to molecules as the power (alleged) of melatonin to put one to sleep, reflux of stomach acid is the cause heartburn.. There are many other examples of the influence of this grammar and its discourse of molecules and causes, for example eating a banana during a tennis match, using cortisone to reduce the inflammation in a cartilage, and so on.

An Organism or O-grammar: Current Western discourses make use of a third grammar, that in which the basic powerful particulars are organisms. While it has, so to say, its natural domain of application in discussions about animals it has some important uses in discourse about human beings. Animals are agentive and act teleologically, while molecules do not. Yet animals do not act intentionally in the full sense that would bring into play the grammar of responsibility except in rare cases. Responsibility talk addressed to family pets is surely metaphorical. When addressed to certain primates, such as domesticated chimpanzees it may have a deeper significance, widening the scope of the domain of moral agents. We also use responsibility grammar for talking about, though not usually to, neonates. Babies act for an end but surely not for a purpose.

Not so long ago there was a fourth grammar in common use., the Spiritual or S-grammar. The basic categories recognized in this grammar, were God, the soul, sin, redemption and the like. This grammar, as an acceptable and unquestioned way of shaping one's thoughts and actions, is now confined to certain rather restricted tribes and regions, for example the Mormon community in Utah. One notices, however, that the terminology is still in widespread used for rhetorical purposes, for example in the speeches of candidates for the United States Presidency.

We have a loose cluster of grammars that set the standards of proper discourse for the human domain, the $P$, the $O$ and the $M$ grammars. Each has variants, and in certain circumstances they fit together into hierarchies, and, in other circumstances, they complement one another.

These grammars include taxonomies, classification systems for categorizing the sorts of entities that comprise their domains. A user of the P-grammar must presuppose that there are intended actions, classifiable into various types, that can be identified in the flow of human activity. The O-grammar user

${ }^{2}$ I owe notice of the Shaver dimensions to M. P. Spackman. 
presupposes that there are bodily behaviors, also classifiable into types, and found amongst the behavior of pets and wild animals too. When someone uses the M-grammar to describe some aspect of their life, say a Chronic Fatigue Syndrome sufferer talks about organo-phosphates damaging the immune system, the reality of molecular exchanges in organ systems and the hierarchical clustering of molecules is presupposed.

The three grammars must also include principles of sequence and order among basic and dependent particulars. In P-grammars these include semantic and syntactic rules and moral imperatives, which are used to shape sequences of meaningful actions. Thanks to the work of the ethologists we now see the lives of animals teleologically in terms of repertoires of actions directed towards maintaining their forms of life. This would be reflected in the O-grammar. In M-grammar sequences of chemical phenomena are understood as shaped by causal processes and described by causal laws. Only in the M-grammar do we have the means to provide causal explanations of the conventional sort, in which some prior state of the system brings about a present or future state.

\section{Meta-discourse or "Human Sciences"}

Since scientific psychology is itself the product of the cognitive activities of human beings is must be applicable to itself. Human sciences, according to our point of view, must include discourses about discourses. If the cognitive performances of ordinary life are shaped by implicit commitment to the P-, Oand M-grammars, these are the organizing principles of the folk psychology that ordinary people use to manage their lives. We could call these "primary discourses". What then of the grammars that shape the activities of psychologists researching the cognitive activities of ordinary people going about their ordinary daily business?

When we examine examples of psychological research we find that there are broadly speaking two sets of explanatory concepts in use.

a. some phenomena are analyzed into cause-effect pairs. ${ }^{3}$

b. some phenomena are analyzed into rule governed sequences of meanings.

A psychological problem is usually identified by the use of the concepts of meanings and rules, which control much of our ordinary vernacular, but subsequent research programmes tend to be couched in terms of causal concepts. However, since there are no mental causes and effects, according to the discursive point of view (they appear only as an illusion produced by using causal concepts to redescribe what are actually discursive phenomena), these concepts are appropriate only for describing and explaining events and processes in the material world, and should therefore be restricted to discourses using the O- and the M-grammars. By the same argument the use of concepts from the meanings and rules repertoire should be restricted to discourses using the P-grammar. Mosquitoes act purposively but not intentionally, and so do babies. Acids act causally but neither purposively nor intentionally.

\footnotetext{
${ }^{3}$ Fathali M. Moghaddam (2006, pág. 840) has used the phrases "performance capacity" and "performance style" to make this distinction.
} 
If we are talking about meanings there is no place for causes, and if we are talking about molecules there is no place for reasons.

I believe that most of this secondary discourse is shaped by the same trio of grammars as shapes the primary discourse, namely $\mathrm{P}-$, O- and M-grammars. Psychologies, in their historical and contemporary variety, are among the genres of this secondary discourse. Some favor the cluster of P-grammars (and so value folk-psychological explanations and analyses), others favor the O-grammar and so emphasize sociobiology and ethology, which yet others favor the M-grammar and psycho-neurology, looking for explanations of this or that feature of human life in terms of neurotransmitters and the like.

Seen thus there is the possibility of tertiary discourse genres, shaped by the same P-, O- and Mgrammars, amongst these is the psychology of psychology. This is no fantasy. For example there is the study by Derek Edwards and Jonathan Potter (1992), in which they examine the psychological character of psychologists' discourses about psychological phenomena, from a discursive point of view.

An example of a tertiary discourse using both $\mathrm{P}-$ - O- and M-grammars would be some current discussions of the role of Freud in Freudian psychology, with his cocaine addiction (M) and his interest in antiquities $(\mathrm{P})$.

\section{"Mind-body" Ties: Three Links between P, $O$ and $M$ discourses}

We are now in a position to deal with one of the most persistent problems in philosophy -the relation between mind and body. This has been seen to be a problem since we seem to be forced to admit the truth of two incompatible theses. Mental and material phenomena seem to be radically different in kind. For example, thoughts are weightless, quite free of the power of gravity. Limbs are locked in the gravitational field of the earth. Yet mental processes, such as deciding to throw a ball seem to lead to material processes, the hand and arm moving in such a way as to project the ball into something like the trajectory the thrower intends. Injuries to the body seem to be the cause of painful sensations. Molecules of acetyl-salicylic acid, aspirin, seem to be effective in eliminating the pain. And so on, through a huge catalogue of ways that the mental aspects of a person's being are inter-related with the material aspects. Mental and material phenomena seem to be causally related to one another. If they are radically different in kind how could such causal relations possibly exist? In order for a relation to be causal. Not only must there be a regularity in the pattern of their occurrence, but there must a generative, observed or hypothesized, between the occurrence of the one and the occurrence of the other. But if there are only meanings and molecules in the universe the generative mechanisms would have to be either a sequence of meanings or a sequence of molecular transformations. The problem simply reappears when we think of how meanings and/or molecular happenings could be related to either kind of mechanism.

The situation seems irresolvable. It is easy to see how philosophers of psychology could be driven to adopt one or other extreme solution denying the reality of the distinction between mental and material phenomena on which the existence of the problem depends. If there are only material phenomena there is no fundamental problem. If there are only discursive phenomena there is no fundamental problem either. However, a radical materialism nor the post-modern reduction of everything to texts are convincing. 


\section{Rethinking the Problem}

The project of setting up a hybrid science, in which the symbol using capacities of human beings are brought into a unified scheme with the organic aspects of members of the species homo sapiens, demands the dissolution of the mind-body problem, somehow setting it aside as an illusion, based on a mistaken presupposition. The trick upon which the possibility of a unified cognitive science depends is to shift the focus from entities to discourses. We have already encountered the metaphor or leading idea with which the unification of the whole field of psychologically relevant discourses is to be accomplished, the metaphor of cognitive tasks and neural tools. It is not the only candidate for a unifying principle. In this section some other possibilities are examined, each having a role in the total project.

Having shifted focus of our enquiries from the misconceived puzzle about how two wholly disjoint substances could interact, and avoiding the complementary pitfall of the attempt to build a human science on the basis of one or other of these alleged substances exclusively, we can turn to examine ways in which the Person-based discourse, the Organism-based discourse and the Molecule-based discourse are related to one another. It seems to me that there are at least three ways in which links are in fact established between these ways of talking that currently dominate the discourses of the human form of life and its scientific investigation. There is the task-tool metaphor by which tasks defined in terms of the $\mathrm{P}$-discourse are accomplished by tools described in terms of the $\mathrm{O}$ - and $\mathrm{M}$-discourses. For example, the task may be to recall as accurately as possible the events of yesterday, a task for which such bodily organs as the hippocampus and the entorhinal cortex are the means. Then there is the way in which dispositions and powers defined in the P-discourse are grounded in structures, states and processes described in $\mathrm{O}-$ and M-discourse terms. Ability respond to the individuality of a face is grounded in the structure of the parvo-cerebral tract, linking the visual cortex with the frontal lobes. The third inter-relation appears in the way that classificatory systems applicable to the entities, states and processes describable in the $\mathrm{O}$ - and $\mathrm{M}$-discourses are dependent on classifications of beings which are identified in the first instance as belonging to types defined in the P-discourse. For example, only if we can already identify an emotion such as anger, can we try to locate the regions in the limbic system that are activated when that emotion dominates someone's thought and feelings.

\section{The task-tool link}

The idea that cognitive tasks often require the use of material tools introduces the metaphor of "brain-astool".

Consider first of all the way we human beings carry out certain cognitive tasks, such as adding up a bill. We are accustomed to think of a pocket calculator as a tool for doing sums. But since that gadget is a prosthetic device, accomplishing cognitive tasks formerly performed by our brains, it seems entirely appropriate to apply the same concept to the brain, or a relevant region of it, when we are engaged in performing the cognitive task without using a prosthesis. A certain electronic device is a "calculator" only in relation to the task it is used to perform. Similarly a certain region of the brain is the organ of calculation only in relation to the task we use it to perform.

Material tasks also engage persons as agents. There too we make use of material tools. Some of these are prostheses for other body parts than the neurological. For digging we need spades. They are 
prostheses for hands, to which, in the absence of spades, we are obliged to have recourse, even now. Pieces of iron are "spades" only in relation to the task they are devised to perform.

There are some tools which far outstrip their prosthetic ancestors, for both cognitive and material tasks. Bulldozers are spades of a sort, but of another order altogether when the task in hand is shifting earth. The same is true of computing machines when the task in hand is arithmetical or the reliable storage of vast amounts of data.

Finally there are cognitive tasks for which we use cognitive or symbolic tools, for instance reasoning carried on with propositions. At this point the simple task (P-grammar) / tool (M-grammar) scheme seems to be in need of further development. To produce a statement, expressing a proposition, which is to serve as a tool in the task of solving a problem, is to engage in a task using a material tool, one's brain. Here we seem to have the use of a tool to produce a tool. This, too, is a metaphor with a familiar origin in industry.

What advantages does the task/tool metaphor have over other ways of expressing the role of $\mathrm{O}$ - and $\mathrm{M}$ entities and states as enabling conditions for P-activities? ${ }^{4}$ People do not generally talk of their brains as tools. However, the point of introducing a metaphor is to extend the power of the existing language to cope with new insights and situations. Boundaries that seem to be impenetrable need to be examined. The metaphor of body parts as tools seems unproblematic in such a piece of advice "If you can't find a trowel, use your hand to scoop out a hole to plant the seedling". The idea of "tool and task" seems already to be fully formed in the common injunction to someone stuck in some problem: "Use your loaf!", meaning "Use your head [brains]". "Brain as a tool" is the scientifically innovative or creative concept that comes from the extensions of the "Use your ..." metaphor inviting us to look on our brains in a new way. Philosophical justification can be found in the prosthesis argument, set out above. Since calculator, electronic organizer and even one's pocket diary are tools for cognitive tasks, though there are cognitive skills required to use them, we can also use our brains as prostheses for prostheses, stand-ins for "extrinsic" cognitive tools, for example, by trying to remember the appointments recorded in a mislaid diary. The brain or one of its modules is functionally equivalent to something which it is not at all controversial to classify as a tool.

Could we find a place for the program of Artificial Intelligence in the hybrid psychology I have been describing? According to discursive psychology mentality is, for the most part, best construed as symbolic manipulations that are both intentional and normative. The models constructed by "knowledge engineers" are analogues of cognitive processes. Programs are written which, when run on a computing machine, lead to states of the machine that can be construed by a human operator as answers to cognitive problems. Successful projects of this kind can serve a double purpose in psychology. The programs can be used as sources of hypotheses about the formal grammars of task setting, rule accessing and expressive activities generally. This application develops naturally from the demands of devising a program to simulate some human activity, an essential intermediate step being the writing a hypothetical set of rules, the following of which would lead to the required result, a state of the machine which can be read as "an answer" to a question expressed as an initial state of the machine.

Successful projects in Al can also be recruited to the project of cognitive science, as the source of schematic representations of the material properties of the tools used in discursively defined projects.

\footnotetext{
${ }^{4}$ My understanding of the task-tool metaphor was greatly advanced in discussions with Bennett Helm and John Deigh.
} 
Since many of these tools are material systems found at various levels in the brain, the Al models can, in some cases, serve as the source of important and perhaps testable hypotheses about brain architecture and brain functions.

\section{Dispositions, Powers, Skills and Capacities, and their Material Groundings}

In colloquial English the word "disposition" is usually used to refer to a person's personality and personal style. It is also sometimes used, in phrases like "I am disposed to let you off the penalty", to mean something like "I am ready to ...". In philosophy of psychology the concept was used in a much more general way (Ryle, 1949). It was used as a catch-all term for all those properties which are displayed only under certain conditions: "If such and such conditions occur then such and such behavior will be displayed".

People have powers to act, they have skills for performing tasks properly, and they have capacities of various sorts. In each case the common feature of all these attributes, ascribable in discourses governed by the P-grammar, is the conditionality of the display the property so ascribed. So for every power, skill, capacity and so on, we can offer a dispositional formulation in "if ... then ..." terms, to express the conditional aspect of the attribute.

This formulation capture only the minimal sense of these terms, since each has further implications. For instance the exercise of a person's powers are not just conditional on the coming to be of certain states of affairs, but the person is the active source of the behavior. "Jim has the power to jump that fence" implies that if Jim is minded he is able to jump the fence. But Jim must be so minded. If he jumps it is his act, and not the effect of some extrinsic cause. ${ }^{5}$

Cognitive capacities, powers and skills are grounded in brain states, structures and processes. Here we have another way of binding the P-grammar to the O- and M-grammars. For example cognitive skills are described in terms derived from the P-grammar. It is persons who decide wisely, to up accounts correctly and so on. These skills are grounded in permanent neural states and patterns of dendrites in the brain. When brains are damaged cognitive skills are affected, even lost.

Though it is an obvious truth that the brain must be in a certain state for cognitive activities to be performed one has to be cautious in assuming that that is also a sufficient condition. All sorts of other conditions must be in place, such as the presence of other people in active conversational engagement with the thinker. But one must also be cautious in how one interprets the many studies on loss of cognitive skills by virtue of brain damage. One would think it would be obvious that because a certain psychological skill cannot be exercised if a certain part of the brain is damaged, that when the person is exercising the skill, that part of the brain is the module that is the tool in question. If the bike chain breaks the bike no longer provides transport, but a bike chain alone will not afford locomotion. A moment's reflection tells us that the lesion that stultifies the proper exercise of the skill may be just one aspect of the whole mechanism, and indeed perhaps a minor part at that.

The disposition-grounding link and the task-tool link are connected in that powers exercised in tasks are grounded in neuro-physiological mechanisms which are thereby the relevant tools, or parts the relevant tools.

\footnotetext{
${ }^{5}$ Again see Moghaddam's distinction between capacity and style.
} 


\section{The Taxonomic Priority Thesis}

This thesis expresses in general terms the classificatory technique by which neural states, structures and processes are identified as relevant to cognitive processes. By the use of the Taxonomic Priority Thesis, the proper tools can be picked out from among all the available material things as just those relevant for the tasks in hand. The molecular bases of memory, for instance, can be identified only if they are picked out in relation to acts of remembering performed by the people whose brain states and processes are being investigated. Similarly we can only identify certain features of people's brains as abnormalities if we have a way of identifying abnormal kinds of speech or conduct. Unless we could identify cases of people having word finding problems we could never identify a tangle of plaques as the relevant abnormality for Alzheimer's Condition, nor damage to the immune system as the relevant abnormality for Chronic Fatigue Syndrome.

In general the criteria of identity for states, processes and structures of the P-discourse exercise "taxonomic dominance" over the criteria of identity for neural states and processes relevant to psychology, that is for the M-discourse. Relevant neural states and processes are picked out by attention to the cognitive states and processes that are occurring. This the Taxonomic Priority Thesis. It has the effect of making the relation between mental states and processes and the relevant brain states and processes a necessary relation, that is it is conceptual not empirical. This is an important point that needs spelling out. If the relation were empirical each "side" of it would have to be able to be picked out independently of the way the other is identified. Then research might reveal that there was a correlation between them. In medicine there are plenty of examples of this kind of discovery. For instance, we identify coffee drinking according to certain criteria, and we identify Parkinson's disease by another and different set of criteria. These sets of criteria have nothing to do each other. Research has established a very good correlation between coffee drinking and a low incidence of developing Parkinson's disease. However if we use a PET scan to pick out the parts of the brain that are activated when someone is reading, the criteria for identifying these parts include the criteria for knowing whether someone is reading. It is a matter of logic that these are parts of the "reading machine". This way of picking things out has been called "top-down" classification.

There are ways in which such taxonomic relations, once established, are protected against disturbance. The most important has a central role in the establishment of empirical research projects in neuroscience. Here is how it works: suppose we do an experiment on a subject, say a PET scan, while the subject is performing some cognitive task, say calculating. The taxonomic priority thesis allows us to identify what is revealed in the PET scan as among the relevant neural processes for calculating. Imagine that we repeat the experiment on the same subject on another occasion and find a different neural process seemingly showing up in the PET scan. Do we abandon the thesis? No. We save it by the hypothesis that there is a so-far unobserved neural process in common to both occasions, and then we set about trying to find it. The case is somewhat different if we repeat the experiment on a different subject and get a different result. In that case we tend to partition the population into two groups, for each of which the TPT holds. For example the finding that men and women read with different parts of their brains is not permitted to upset TPT. The problem is resolved simply by partitioning the human population into two groups by gender with respect to the P-discourse defined skill of reading. ${ }^{6}$ Thus we have men readers and women readers as two $\mathrm{P}$-discourse categories each with their relevant but different brain mechanisms.

${ }^{6}$ This point became clear to me during a discussion with Kevin Weinfurt 


\section{Psychology as a Hybrid Science}

Having looked at three ways in which the P-, O- and M-grammars can be bound together into a comprehensive conceptual system fit to serve as the basis of a science, what kind of science will it be? Since doing psychology is a human activity, the same principles should apply it, as to any other pattern of action which realizes well established story-lines. If psychology is a cluster of narrations: what are the relevant grammars? It would surely be unacceptable to most psychologists to describe their professional activities in the O- and M-grammar. Only if presented in the frame of the P-grammar could credit be claimed for a successful research project, since only in a frame in which the concept of "person" picks out the basic active particulars does the concept of responsibility have a place, and hence the concept of credit.

There is, in a sense, only one stream of action. As described in the P-grammar it displays such phenomena as "emotions", "attitudes", "memories", "items of knowledge", "performance of athletic feats", and so on. Using the metaphor of a stream we might think of these phenomena as eddies, whirlpools, froth and waves in the continuous flow that dries up only on the brain death of the actor. Some are ephemeral and others more enduring.

It seems that the basic type-hierarchy that has evolved in psychology in recent years has two main branches, one material and one discursive.

The first branch consists of the agents that produce material processes, in the environmental and in the bodies of organisms. The active entities are molecular clusters of a huge variety of types. For this branch we have recourse to a discourse-style shaped by the molecular grammar. The mode of action of Mentities is causal and deterministic.

The second branch consists of the agents to which we assign goal-seeking capacities, and for our purposes the basic agents are predominantly whole organisms. For this branch we have recourse to the $\mathrm{O}$ - or organism grammar. The mode of action of O-entities is teleological, seeking practical goals, such as the bear who looks for homey.

The third branch consists the agents who produce discursive patterns, normatively constrained streams of meaningful actions, that in essence are the psychological practices of human beings, singly and in groups. The active beings are human beings as intentional agents, persons. For this branch we have recourse to the $\mathrm{P}$ - or person grammar. The mode of action of P-entities is intentional, that is by recourse to meanings and rules.

As singular sources of action and the embodied centers of perceptual fields people are centers of discursive activity. But, according to this ontology, when considered in relation to discursive activities, people are not psychologically complex. They produce complex private and public intentional and ever changing and evolving structures of discursive acts. Those that are private we are inclined to call mental, thoughts and feelings, but qua intentional acts they differ not at all from public acts, except in so far as the interactor whose uptake completes the action as act is, in the case of private acts, oneself. We produce our own minds, just as we produce conversations, tennis matches, orchestral performances, ditch digging and so on with others.

There are no hidden mechanisms in the P-domain, according to the point of view being developed here. The program of Scientific Realism is not to be fulfilled by postulating an imperceptible realm of 
unobservable mental mechanisms, as Freud did in introducing the unconscious mind. Scientific Realism in psychology is achieved by making use of the task/tool metaphor in proposing neural mechanisms as among the tools that people use for accomplishing their P-grammar tasks. The workings, but not the roles, of these tools are described and explained in the $\mathrm{M}$ - and O-grammars. Their domains are tightly woven together in that O-processes are routinely accounted for by recourse to hypotheses about hidden molecular processes. Since at least some M-processes are observable in principle, the proposal of a hidden mechanism explanation can often lead to a research program in an effort to verify the verisimilitude of the working model of that mechanisms on which the hypothesis depends.

Neither branch of the hybrid psychology can colonize the other. Human beings in the molecular ontology are machines with no moral attributes. Brains in the person ontology are tools for use in tasks set discursively by people who are morally responsible for what they do with them. Giving priority to the Pgrammar preserves the outlines of human life as a moral world, while finding place for our brains as tools for morally constrained tasks. However, if we were to prioritize either $\mathrm{O}$ or the $\mathrm{M}$ grammar, people as a category disappear from the world of psychology, taking the moral universe with them. .

\section{Referencias}

Bennett, Maxwell R. \& Hacker, Peter M. S. (2007). Philosophical Foundations of Neuroscience. Malden, MA: Blackwell.

Bruner, Jerome S. (1986). Actual Minds. Possible World. Cambridge, MA: Harvard University Press.

Danziger, Kurt (1990). Constructing the Subject. Cambridge: Cambridge University Press.

Edwards, Derek \& Potter, Jonathan (1992). Discursive Psychology. London: Sage.

Garfinkel, Harold (1967). Studies in Ethnomethodology. Englewood Cliffs NJ: Prentice Hall.

Gibson, James J. (1966). The Senses Considered as Perceptual Systems. Boston: Houghton Miflin.

Harré, Rom (2004). Cognitive Science: A Philosophical Introduction. London and 1000 Oaks: Sage.

Moghaddam, Fathali M. (2006). Performance capacity and performance style: Looking back and moving forward in psychology. Theory and Psychology, 16, 840-846.

Polanyi, Michael (1958). Personal Knowledge. Chicago: Chicago University Press.

Ryle, Gilbert (1949). The Concept of Mind. London: Hutchinson.

Shaver, Kelly G. (1985). The Attribution of Blame: Causality, Responsibility, and Blameworthiness. New York: Springer-Verlag.

Shweder, Richard A. (1991). Thinking through Cultures. Cambridge, MA. Harvard University Press.

Wittgenstein, Ludwig (1953). Philosophical Investigations. Oxford: Blackwell. 


\section{Historia editorial}

Recibido: 25/05/2010

Aceptado: 01/06/2010

\section{Formato de citación}

Harré, Rom (2010). Hybrid Psychology: The marriage of discourse analysis with neuroscience.. Athenea Digital, 18, 33-47. Disponible en http://psicologiasocial.uab.es/athenea/index.php/atheneaDigital/article/view/665.

\section{SOC}

Este texto está protegido por una licencia Creative Commons.

Usted es libre de copiar, distribuir y comunicar públicamente la obra bajo las siguientes condiciones:

Reconocimiento: Debe reconocer y citar al autor original.

No comercial. No puede utilizar esta obra para fines comerciales.

Sin obras derivadas. No se puede alterar, transformar, o generar una obra derivada a partir de esta obra.

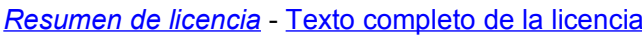

